\title{
$3^{\text {po }}$ EuCheMS: Participe Com o Seu Conhecimento
}

Os congressos organizados pela EuCheMs têm-se revelado um sucesso em termos de número de participantes e qualidade científica das comunicações apresentadas. Nesta senda, a German Chemical Society (GDCh) que organiza o $3^{\text {rd }}$ EuCheMS em Nuremberga de 29/8 a 02/09/2010, criou um blogue e uma série de filmes com o objectivo de promover o evento e envolver a comunidade química europeia neste fórum de discussão. O blogue poderá ser acedido pela seguinte morada:

http://euchems2010.wordpress.com/
Para além da natural promoção do congresso, a organização pretende com este blogue dinamizar e envolver a comunidade na preparação da discussão científica que irá decorrer em Nuremberga. Assim, todos poderão contribuir com breves notícias sobre artigos ou descobertas que considerem interessantes, assim como comentar as existentes. Para esse fim, basta enviar o texto com indicação de autoria "Guest Article by ..." para:

http://euchems2010.wordpress. com/2009/09/01/little-update-fromwissenschaftsforum/
Mais informação estará disponível na forma de filmes na página do congresso: www.euchems-congress2010.org ou no youtube (http://www.youtube. com/watch?v=|2zb-odl-pY).

"Participe com o seu conhecimento nesta comunidade de químicos europeus"

GQJ

(Grupo de Químicos Jovens)

\section{Apresentação da Página Web do Grupo de Químicos Jovens}

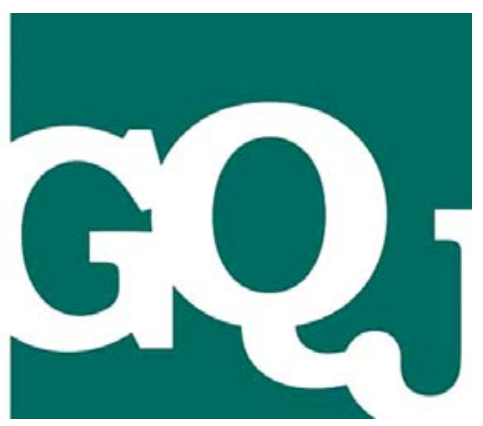

A página Web do Grupo de Químicos Jovens (GQJ) está finalmente disponível em www.spq.pt/gqj/

Esta nova ferramenta irá permitir ao GQJ uma presença e contacto mais próximos da comunidade de químicos portugueses, com especial ênfase nos jovens. A página está dividida em várias secções:

PYCheM - nesta secção podem encontrar informação sobre o Portuguese Young Chemists Meeting. Está disponível informação de carácter geral, bem como o livro de abstracts e as fotos do 1PYCheM que se realizou em Outubro de 2008. O poster do 2PYCheM com link para a página do encontro irá estar disponível brevemente.

ChemRus - esta é uma das áreas em que depositamos mais expecta- tivas para uma interacção estreita com a comunidade científica e escolar. Nesta secção estarão acessíveis experiências de Química com ficha pedagógica/científica e respectivo vídeo. E espera-se a contribuição futura de toda a comunidade química portuguesa para o aumento do portfólio de experiências.

JobChem - esta secção oferece uma breve descrição de vários motores de busca e sites de oferta de emprego onde os jovens químicos podem procurar emprego em Portugal e no estrangeiro. Existe também um espaço onde entidades públicas e privadas poderão colocar directamente as suas ofertas de bolsas e empregos. Por exemplo, agradecemos aos diferentes responsáveis de projectos com bolsas que façam o download da ficha que se encontra na página e a enviem preenchida para jobchem.gqj@spq.pt

CheMba - esta secção surge com a intenção de oferecer um espaço de discussão para jovens químicos que queiram desenvolver projectos de empreendedorismo. CheMba oferece a possibilidade de colocar estes futuros empresários em contacto com profissionais com formação em gestão de forma a discutir as suas ideias, ponderar os desafios e procurar possíveis soluções (email chemba.gqj@spq.pt). Esta secção apresenta ainda uma sé- rie de links para sites com diferentes programas nesta área (CoHiTEC, Adl, Parques Tecnologia, Concursos de ideias, apoios a criação de empresa, fontes de investimento).

PYCA - toda a informação relativa ao Prémio Químicos Jovens / Portuguese Young Chemists Award irá estar disponibilizada nesta área. No futuro, com a realização de diversas edições do prémio, será criada uma lista de vencedores com os respectivos artigos e fotos alusivas à cerimónia de entrega dos prémios.

EYCN - este espaço será reservado para apresentar e divulgar as actividades da European Young Chemists Network (EYCN). A EYCN faz parte da European Association for Chemical and Molecular Sciences (EuCheMS). Os diversos países são representados por delegados das várias sociedades nacionais. O GQJ tem como parte da sua missão assegurar a representação portuguesa.

Join GQJ - O GQJ tem um ano e meio de existência. Durante este tempo viveu da disponibilidade e perseverança de alguns jovens químicos que tentaram criar um espaço dentro da $S P Q$ que dinamizasse e desse mais visibilidade aos jovens químicos. No entanto, para continuar a crescer e a desenvolver actividades, este Grupo 
precisa que mais jovens pertençam formalmente ao Grupo. O aumento do número de sócios (< 35 anos) pertencentes ao GQJ levará a um enriquecimento da discussão sobre as actividades do Grupo e sobre a sua continui- dade no futuro. Para oficializares a tua adesão ao GQJ envia um fax (+351 217952349) ou email (sede@spq.pt) indicando o teu nome, $n^{\circ}$ de sócio da $S P Q$ e a intenção de pertenceres ao GQJ.
Contamos com a tua visita e participação!

Grupo de Químicos Jovens Carlos Baleizão, Frederico Ferreira, Pedro Gois

\section{Prémıo Químicos Jovens 2010 / Portuguese Young Chemists Award 2010}

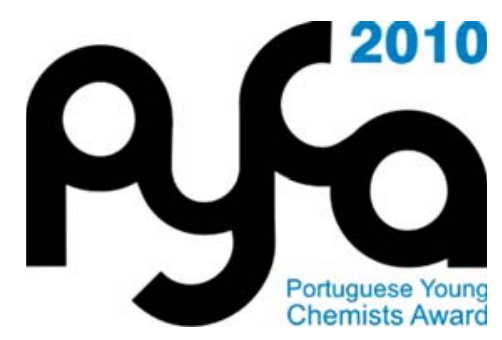

O Grupo de Químicos Jovens tem o prazer de anunciar a primeira edição do Prémio Químicos Jovens / Portuguese Young Chemists Award.

Este prémio visa promover a excelência da Química desenvolvida por Jovens Investigadores, com especial enfoque na divulgação e impacto desta disciplina na Sociedade. Com esta iniciativa, o Grupo de Químicos Jovens (GQJ) pretende dinamizar e consciencializar os jovens químicos para a importância de divulgar ciência, com enfoque na Química.

O prémio destina-se a recém-doutorados em Química e áreas afins que cumpram cumulativamente as seguintes condições:

x Tenham nacionalidade Portuguesa ou, caso tenham outra nacionalidade, tenham obtido o grau de doutoramento numa Universidade Portuguesa.

x Tenham menos de 35 anos a 31 de Dezembro de 2009.

x Tenham obtido o grau de doutor entre 1 de Janeiro de 2008 e 31 de Dezembro de 2009.

× Sejam sócio da SPQ com quotas regularizadas.
O júri será constituído pelo Professor Jorge Morgado do Instituto Superior Técnico e Editor do Boletim da Sociedade Portuguesa de Química (SPQ), pelo Professor Eurico Cabrita da Faculdade de Ciências e Tecnologia da Universidade Nova de Lisboa e pela Doutora Mónica Bettencourt Dias do Instituto Gulbenkian de Ciência.

A avaliação terá como base a qualidade de um artigo de divulgação científica elaborado pelo candidato a partir do trabalho desenvolvido no seu doutoramento, tendo em conta o impacto do trabalho exposto e a capacidade de comunicação com a sociedade.

O prémio será entregue no " $2^{\text {nd }}$ Portuguese Young Chemists Meeting" (2PYCheM), que se realizará em Abril de 2010 em Aveiro.

O candidato vencedor, para além de ver o seu artigo publicado no Boletim da SPQ, receberá a oferta de um ano de quotas da SPQ. O candidato distinguido terá ainda a possibilidade de apresentar uma comunicação oral (Comunicação Oral convidada) no

\section{Datas Importantes}

Prazo para envio de candidaturas: 1 a 31 de Janeiro de 2010 Divulgação dos resultados aos candidatos: 15 de Março de 2010 Entrega do prémio: $21-23$ de Abril de 2010, $2^{\text {nd }}$ Portuguese Young Chemists Meeting decorrer do 2PYCheM, sob a mesma temática do seu artigo vencedor. O júri poderá atribuir Menções Honrosas, premiando outras candidaturas que se tenham destacado, e que se traduzirão na publicação dos respectivos artigos no Boletim da SPQ.

Os jovens químicos que tenham a intenção de se candidatar podem obter mais detalhes através do "Regulamento Geral" e do "Regulamento PYCA 2010" disponíveis na página do GQJ em www.spq.pt/gqj

\section{Contamos com a tua participação}

Grupo de Químicos Jovens

Carlos Baleizão, Frederico Ferreira, Pedro Gois

Esteja sempre actualizado e saiba o que se passa no mundo da Química com o nosso Boletim trimestral. Vá a www.spq.pł e torne-se sócio. 